Síntese - Rev. de Filosofia

v. 37 N. 118 (2010): 215-226

\title{
DE DEUS AO REI: O DIREITO SAGRADO DO MANDO (IMPLICAÇÕES TEOLÓGICO-RELIGIOSAS NA TEORIA POLÍTICA MODERNA)
}

[From God to the King: the divine right to rule (theological and religious implications in modern political theory)]

Marcos Antônio Lopes ${ }^{1}$

Resumo: Na perspectiva dos cruzamentos e fusões de culturas políticas diversas que se processaram no curso de uma longa história, este artigo analisa aspectos da inovação doutrinal legitimadora do Estado monárquico no século XVII. Tal inovação é representada, fundamentalmente, pela teoria do direito divino dos reis, teoria que deve ser contraposta a um status social da realeza moderna que há muito era reconhecido na prática por seus súditos.

Palavras-chave: Realeza sagrada, simbolismo político, política e religião.

Abstract: Based on the crossing and merging of the various political cultures that occurred in the course of a long history, this article analyzes aspects of the doctrinal innovation legitimizing the Monarchic State in the XVIIth Century. Fundamentally, such an innovation is represented by the theory of the divine right of kings, which must be opposed to a social status of modern kingship that, in practice, had long been acknowledged by the kings' subjects.

Key-words: Sacred kingship, political symbolism, political and religion.

\footnotetext{
${ }^{1}$ Doutor em História pela USP. Pesquisador do CNPq (Bolsista Produtividade em Pesquisa). Professor na Universidade Estadual de Londrina. Artigo submetido a avaliação no dia 02/04/2009 e aprovado para publicação no dia 10/06/2009.
} 
$\mathrm{D}$ esde o seu surgimento, o cristianismo reconheceu que todo poder é oriundo de Deus e a ele pertence, segundo a consagrada expres são do apóstolo Paulo. ${ }^{2}$ No século XVII, época do triunfo incontestável dos reis absolutistas, o ato de governar se revestia de uma natureza sacramental. Sobre a autoridade política dos reis recaía a responsabilidade de assegurar a harmonia entre a sociedade dos homens e a ordem divina desejada por Deus. Todo monarca, independentemente de seu valor pessoal e da qualidade de sua administração, era concebido como uma figura sagrada. Bossuet (1627-1704), um dos mais representativos ideólogos do poder régio por direito divino, dizia que qualquer ato de rebeldia contra o príncipe cristão - ainda que apenas em pensamento - era atitude sacrílega e, portanto, um atentado contra a ordem sagrada das coisas. ${ }^{3}$ Segundo a análise de Antonio Candido, o direito divino da realeza sagrada e cristã, um dos três elementos que compõe a estrutura do mando, é princípio "... inato e de ordem biológica, pois é hereditário e se transmite pelo sangue". ${ }^{4}$ A teologia política ${ }^{5}$ expressa por Bossuet alcançou uma formulação ideológica complexa na teoria do direito divino dos reis, teoria que, ao lado do simbolismo místico da tradição judaico-cristã, também incluía elementos da racionalidade política moderna: o conceito de soberania, por exemplo. Se a monarquia por ele apregoada - com a energia apropriada a um teólogo quase residente no palácio do rei -, só se submeteria a Deus, nem por isso o Estado e o governo dos homens deixava de ser "um trabalho de razão e inteligência", conforme afirma o historiador norte-americano Philip Bobbitt. ${ }^{6}$

Acerca dessa doutrina de justificação do poder régio é preciso dizer que ela foi a expressão de uma época que conseguiu conciliar as necessidades de poderes seculares modernos em ascensão com alguns princípios teológico-doutrinais vigentes ao longo da Idade Média. Historicamente, a teoria do direito divino dos reis triunfou a partir do Renascimento, com a ruptura do pensamento político medieval, ruptura esta baseada no enfraquecimento ou mesmo no término da longa série de conflitos e controvérsias entre o Papado e o Sacro Império Romano. Quando esses dois antigos

${ }^{2}$ Cf. HOUX, Jean-Paul. Le roi: mythes et symboles. Paris: Fayard, 1995. p. 245.

${ }^{3}$ Cf. BOSSUET, Jacques-Bénigne. Politique tirée des propres paroles de l'Ecriture Sainte. Genève: Droz, 1967. p. 65.

${ }^{4}$ CANDIDO, Antonio. "A culpa dos reis: mando e transgressão no Ricardo II". In: Novaes, Adauto. (Org.). Ética. São Paulo: Companhia das Letras, 1999. p. 89. A análise de Candido é aplicada à estrutura narrativa de uma obra literária, mas não deixa de ser ilustrativa das considerações que se seguem acerca do processo político.

${ }^{5}$ Por teologia política entenda-se, com Kantorowicz, a forma de pensamento surgida na Baixa Idade Média, a partir do impacto provocado pelo intercâmbio de ideias políticas formuladas por comentadores do direito canônico e civil. Por teologia política compreendese, ainda, as reflexões políticas que se ancoram em religiões reveladas, como é bem o caso do cristianismo e do islamismo. Cf. STRAUSS, Leo. What is Political Philosophy? New York: Free Press, 1968.

${ }^{6}$ Cf. BOBBITT, Philip. A guerra e a paz na História Moderna. Rio de Janeiro: Campus, 2003. p. 108. 
atores deixaram a cena principal da política na transição da Idade Média aos Tempos Modernos, a vontade de Deus passou a se manifestar na terra por meio dos príncipes, mormente na França e na Inglaterra. Ao menos esse era o argumento expresso pelos escritores encarregados de defender os regimes políticos emergentes. Bossuet, por exemplo, alegava que o príncipe deveria perseguir, em suas ações políticas, finalidades espirituais inspiradas pela Providência, como se ele próprio - o soberano - fosse um autêntico pastor de almas. As Sagradas Escrituras seriam o seu farol, o guia seguro para incutir-lhe as virtudes necessárias à formação da consciência do príncipe perfeito.

Os escritores políticos que empreenderam a defesa da causa régia lastrearam os direitos do príncipe numa vontade sobrenatural. Assim agindo, realizaram uma operação intelectual de transferência de antigos valores ou princípios políticos. Com efeito, muitos postulados explicativos da origem divina do poder régio na época do absolutismo fundamentaram-se na cultura política da Baixa Idade Média, e até mesmo em tradições da Antiguidade. A legitimação teológica que até então servira aos jogos simbólicos da Igreja medieval, passou a atender também às novas finalidades políticas das modernas monarquias absolutistas. É por isso que se afirma comumente que, a rigor, nada há de original nos princípios teóricos justificadores do direito divino dos príncipes europeus modernos, seja a defesa de Jaime I, seja a de Bossuet, ou mesmo a de outros escritores políticos europeus adeptos das prerrogativas régias na era do absolutismo. No plano da política, a expressão máxima dessa doutrina é o direito incontestável do comando de um só - o equivalente ao summum imperium na teoria política dessacralizante de Hobbes. Em meio ao processo de constituição de uma nova concepção da sociedade política, a figura do rei encontrou farta tradição histórica para elevar-se. De uma posição ainda de pouca expressão ao longo dos séculos XIV e XV, o príncipe cristão passou ao topo hierárquico da sociedade política. Isso significa que as prerrogativas do príncipe obrigavam todos a se curvarem à sua vontade, mas que ele não estava obrigado pela vontade de ninguém. Foi assim que, ao longo do século XVII, o desejo do príncipe passou a ter força de lei e a ser a própria expressão do direito. $\mathrm{O}$ único limite à sua vontade era a sua própria consciência cristã, o que alguns chamaram à época por "freio moral" da realeza.

A partir do século XVI, o processo de desenvolvimento das estruturas políticas na Europa ocidental levou à existência de uma forma típica de organização política: as monarquias modernas. Tratou-se de uma forma de governo em que o poder político se transmitia hereditariamente - com exceções como a Polônia, onde o processo era eletivo - , e em que, fato marcante, o soberano recebia o seu poder diretamente de Deus. O direito divino dos reis - teoria política fudamentadora do poder nessas monarquias -, foi uma ideologia formada por várias teses referentes a um princípio: o poder e a autoridade reais teriam Deus por fonte exclusiva, sem a 
possibilidade de intervenção popular ou da Igreja. Essa tese acabou resultando em um consistente corpo de ideias ao longo do processo de consolidação das monarquias francesa e inglesa, processo este compreendido entre os séculos XIV e XVII.

Assim sendo, a linguagem política dos primeiros séculos dos Tempos Modernos, pelo que preservou de pressupostos teológicos típicos da Idade Média, esteve fundamentalmente marcada pela permanência de valores antigos. Encontrando-se inegáveis elementos de ruptura nas doutrinas do direito divino - a legitimação da transferência da autoridade e soberania universal do papado ou do império para a monarquia, por exemplo conservaram-se premissas teológicas de outrora, agora voltadas ao serviço de outros interesses. Mas, as ditas premissas teológicas - notadamente conservadoras, sem dúvida - , de forma alguma embaçam a modernidade doutrinal da teoria do direito divino dos reis. Como afirma o historiador da filosofia Alasdair MacIntyre, uma característica muito surpreendente das controvérsias morais e políticas do mundo moderno é o grau em que os inovadores, os radicais e os revolucionários reviveram as velhas doutrinas, enquanto que os seus opositores conservadores e reacionários foram os inventores das novas formas de pensamento. Dessa forma, segue MacIntyre, os teóricos contratualistas e os partidários dos direitos naturais ressuscitaram, ao longo do século XVII, traços de doutrinas medievais, ao passo que a doutrina do direito divino dos reis era, essencialmente, uma invenção dos séculos XVI e XVII.7

Segundo o pensamento de Bossuet, a soberania do príncipe era de uma evidência incontestável, porque ele seria sempre a representação simbólica da paternidade divina. Desse argumento, Bossuet fez derivar a sua teoria do patriarcado. O melhor exemplo histórico que o autor oferece para ancorar sua doutrina numa origem sagrada da realeza encontra-se no livro intitulado Política Extraída das Sagradas Escrituras. O rei é pai de seu povo e “... não há nada entre os homens mais sério nem mais grave que o ofício da realeza". ${ }^{8}$ No Discursos sobre a História Universal lê-se algo análogo: "Com efeito, Ele mantém sua proteção a Isaac e a Jacó. Eles foram seus imitadores (o autor se refere a Abraão), ligados como ele à crença antiga, à antiga maneira de vida que era a vida pastoral, ao antigo governo do gênero humano onde cada pai de família era príncipe em sua casa. Assim, nas mudanças que se introduzem todos os dias entre os homens, a santa antiguidade revivia na religião e na conduta de Abraão e de seus descendentes". ${ }^{9}$ Para Bossuet, a imagem paternal do príncipe faz os ho-

${ }^{7}$ Cf. MACINTYRE, Alasdair. A Short History of Ethics. New York: Macmillan, 1966.

${ }^{8}$ BOSSUET, Jacques-Bénigne. Politique tirée des propres paroles de l'Ecriture Sainte. Op. cit., p. 128.

${ }^{9}$ BOSSUET, Jacques-Bénigne. Discours sur l'histoire Universelle. Paris: Flammarion, 1920. p. 141. 
mens se inclinarem naturalmente diante de sua figura benfeitora. A autoridade paterna do rei se reflete em todos os domicílios. Cada pai de família carrega uma pequena parcela dessa mesma centelha de essência divina, o que revela a importância dada à autoridade paternal. Ela estaria tão intimamente ligada à ordem do absolutismo que Lettres de cachet, destinadas a aprisionar filhos desobedientes, poderiam ser solicitadas pelos pais ao rei. ${ }^{10}$ Essa via da propaganda ideológica definiu evidentes relações entre a autoridade política superior e os milhões de pais de família, chamados a governar seu universo doméstico segundo o mesmo espírito. Pode se falar, então, de mediadores inconscientes do absolutismo. ${ }^{11}$

Desde a Idade Média, os reis franceses receberam a alcunha moral e religiosa de "pais do povo", por suas conhecidas diligências em benefício da parcela mais pobre de seus súditos. Essa expressão entrou para o vocabulário político do Antigo Regime. Como um pai em relação à sua família, ao rei cabia informar-se acerca das necessidades de seus filhos, e até sobre seus anseios mais privados. Para tanto, os príncipes seriam dotados de uma sensibilidade especial que lhes permitiria entrever o que ainda não se revelara aos mortais comuns. O príncipe de Bossuet é como o príncipe dos puritanos ingleses, o "príncipe inspirado" da revelação bíblica: "Assim, Deus permite ao príncipe descobrir as tramas mais secretas. Ele tem olhos e mãos em toda parte. Nós vimos que os pássaros do céu lhes transmitem o que se passa. Ele tem recebido de Deus mesmo, para o uso nos negócios, uma certa penetração que faz pensar que ele adivinha. Ele penetra as intrigas, seus longos braços vão encontrar seus inimigos nas extremidades do mundo; eles irão atirá-los no fundo dos abismos. Não há absolutamente asilo seguro contra uma tal força". ${ }^{12}$

De acordo com a cultura política do absolutismo de direito divino, um rei deveria refletir na terra a própria imagem de Deus. Conforme apregoava Bossuet, o príncipe cristão deveria atuar como uma providência terrestre: ter as mãos livres para fazer o bem, ao mesmo tempo que atadas para agir no mal. Entre as suas principais virtudes, o rei deveria cultivar a justiça em todas as suas ações. Assim sendo, o exercício do poder poderia ser fonte

\footnotetext{
${ }^{10} \mathrm{Na}$ época do absolutismo "uma forma arbitrária da autoridade real vai se constituir em uma benção para famílias que, às voltas com a libertinagem desonrosa de um de seus membros, desejam evitar qualquer ação da justiça ordinária considerada infamante. $\mathrm{O}$ pedido de prisão através da lettre de cachet torna-se o meio de conciliar a reparação da honra com a privacidade da família”. FARGE, Arlette. Famílias, a honra e o sigilo. In: CHARTIER, Roger \& ARIÈS, Philippe. História da vida privada. São Paulo: Companhia das Letras, 1995. p. 598.

${ }^{11}$ Cf. MUCHEMBLED, Robert. Société, culture et mentalités dans la France Moderne. Paris: Armand Colin, 1993. p. 127. Sobre a realeza patriarcal em Bossuet veja-se CHEVALLIER, Jean-Jacques. As grandes obras de Maquiavel a nossos dias. Rio de Janeiro: Agir, 1999.

${ }^{12}$ BOSSUET, Jacques-Bénigne. Politique tirée des propres paroles de l'Ecriture Sainte. Op. cit., p. 132.
} 
de salvação ou de ruína, conforme o emprego que lhe fosse dado. Foi ao longo da Época Moderna que se produziu na Europa um novo e extenso catálogo de novas virtudes e vícios políticos, a serem atentamente observados pelas cabeças coroadas do período. Maquiavel, por exemplo, em $O$ Príncipe, empreendeu um interessante trabalho de re-elaboração dos valores principescos tradicionais. Mas, não é demais dizer que o seu "catálogo" de valores morais foi rejeitado com ênfase pelos defensores do direito divino dos reis.

Sem dúvida, o poder dos reis ao longo do Antigo Regime foi uma sequência de manifestações simbólicas, um imenso conjunto de códigos e de rituais. Esse simbolismo esteve enraizado no complexo de signos religiosos fazendo da esfera do político um território também religioso. De modo geral, as formas mais freqüentes de enunciar os fundamentos da soberania absoluta dos reis da Europa Moderna trazem proposições do tipo: o direito divino é a teoria segundo a qual se estabelecia que a prerrogativa para governar era uma delegação de Deus ao rei, ficando este desobrigado a prestar qualquer espécie de satisfação a seus súditos; ou, o direito divino era a teoria pela qual o poder vinha diretamente de Deus aos soberanos, sem qualquer possibilidade de intervenção do povo. Apesar de essencialmente corretas, é preciso ampliar essas noções agregando a tais proposições algumas ideias complementares.

Por paradoxal que pareça, as doutrinas da legitimação do poder régio atuaram como instrumentos inibidores do poder do monarca ao longo da Época Moderna. Com efeito, as monarquias absolutistas no Ocidente Moderno estiveram limitadas, tanto pela complexa cascata de particularismos regionais e poderes intermediários dos reinos, quanto pelo assim chamado "freio moral". Além de limitações de ordem prática, como a ineficiência dos aparelhos administrativos, que não conseguiam atuar satisfatoriamente em províncias muito afastadas do centro do poder, atente-se para o princípio de que o rei era o primeiro súdito de Deus. Assim sendo, a ele estavam interditadas, pelos preceitos da religião, quaisquer ações que comprometessem sua condição de rei cristianíssimo. Para Perry Anderson "... a prática do absolutismo correspondia à teoria de Bodin. Nenhum dos Estados absolutos pôde jamais dispor segundo o livre arbítrio da liberdade e das propriedades fundiárias da nobreza e da burguesia à maneira dos tiranos asiáticos do seu tempo". ${ }^{13}$ Com certeza, o depositário do poder nunca foi capaz de desvincular-se de todas as normas pré-fixadas e subentendidas de conduta social, passando a governar sem mais critério que não fosse o do próprio arbítrio. A doutrina do direito divino não os favorecia nesse sentido.

${ }^{13}$ ANDERSON, Perry. "Classes e Estados: problemas de periodização". In: HESPANHA, Antonio Manuel. (Org.). Poder e instituições no Antigo Regime. Lisboa: Fundação Calouste Gulbenkian, 1984. p. 133. 
Em síntese, nas monarquias inglesa e francesa, ao longo da Época Moderna, não se tratou de defender uma autoridade absoluta por meio de uma doutrina legislativa e executiva com poderes ilimitados. Ainda que sua finalidade fosse fundamentalmente oposta, o direito divino pôde atuar também como instrumento de limitação do poder. Na Europa Moderna, um poder ilimitado, no sentido pleno da expressão, determinado por delegação divina, nunca existiu de fato. A monarquia estava limitada tanto pelas intocáveis imunidades de setores privilegiados - como a alta aristocracia das províncias e corporações dos centros urbanos - , quanto pela ineficiência da administração central representada por amplos e heterogêneos corpos de funcionários espalhados pelas diferentes províncias.

O direito divino dos reis encontrou-se "amarrado" em um corpo doutrinal complexo somente muito tempo depois de Bodin ter-lhe dado os primeiros contornos. O longo reinado de Luís XIV foi a época de seu apogeu. Em sua forma mais acabada, como a conheceu o século XVII, tais teorias implicaram um emaranhado doutrinal, tal a complexidade dos postulados defendidos. Que a monarquia era uma instituição de ordenação divina foi algo que, no sistema de crenças da época, não deixava margem para dúvida. Seguia-se o argumento de que o direito de governar advindo de tal ordenação era hereditário e irrevogável. Disso podia-se concluir que o direito adquirido por virtude de nascimento não se perderia por qualquer ação terrena. Assim, a sucessão monárquica devia regular-se pela lei da primogenitura. Segundo tal lei, mesmo que o herdeiro se revelasse com pouca ou nenhuma capacidade para o comando, não podia ter seu poder limitado ou usurpado. Portanto, tratava-se de uma "eleição divina" e, de nenhuma forma, de uma questão de mérito baseada na competência técnica ou eficácia de qualquer ordem. A lei de primogenitura, considera o filósofo Renato Janine, "Não quer dizer que o filho mais velho seja superior ao mais novo - apenas exclui-se de vez qualquer pretensão deste" ${ }^{14}$

De acordo com certos escritos políticos produzidos por defensores do regime, em casos de usurpação, independentemente do tempo decorrido, o direito pertenceria sempre ao soberano destituído, ou a seus herdeiros legítimos, porque fixado pelas leis do nascimento. Desde que o herdeiro viva, lembra John Neville Figgis, ele é o rei por direito hereditário, sem consideração ao tempo que o usurpador tenha reinado. Desses raciocínios conclui-se que a ascendência divina e a transmissão por primogenitura funcionavam como mecanismos inibidores, por um lado, de dissensões entre as grandes casas nobiliárquicas em torno do poder e, de outro, de conflitos internos à casa reinante. Em outras palavras, subentende-se que a monarquia hereditária era um regime político não corruptível pela ação

${ }^{14}$ RIBEIRO, Renato Janine. "O retorno do bom governo". In: NOVAES, Adauto. (Org.). Ética. Op. cit., p. 106. 
de efeitos humanos, e que a soberania pertenceria por inteiro apenas a um rei legitimamente constituído. Apenas a salvação pública estava acima do direito de propriedade e um monarca cristão, em sã consciência, nunca devia agir a seu bel-prazer. Nesse sentido, as ações do rei ficavam limitadas pelas leis consuetudinárias do reino, alertava entre outros Jean Bodin.

Apesar de certos limites, toda lei era uma simples concessão que devia ser entendida como ato espontâneo do rei e todo preceito legal e todos os mecanismos das formas organizativas, como as Assembléias dos Estados Gerais, por exemplo, existia apenas em função direta de seu arbítrio. Mas, entre o que estava disposto pela ideologia e o que era vivido na prática, a distância sempre foi significativa. Para alguns ideólogos do direito divino, qualquer atentado à soberania régia, no sentido de dividi-la ou de alguma maneira limitá-la, implicaria em comprometimento de um mais amplo e eficaz exercício da mesma pelo sucessor. Vale dizer: ainda que o monarca tenha agido despoticamente nesta ou naquela ocasião, era preciso suportálo com paciência bíblica.

Uma monarquia mista, ou que de alguma forma sofresse sensíveis limitações em sua soberania, implicaria uma contradição em seus próprios termos. Dessa maneira, recomendava-se para todos os efeitos a obediência passiva e a não-resistência como as atitudes desejáveis aos súditos, porque de ordenação divina. As resistências à vontade soberana eram vistas como crime de lesa-majestade, acarretando punições exemplares e até a condenação da alma. Mesmo que ocorressem situações em que o rei adotasse preceitos contrários à religião e à fé cristã, intimamente era sempre a Deus que se devia obediência. Mas, pelo preceito da obediência passiva, o súdito devia resignar-se, seguindo o exemplo dos primitivos cristãos, e do próprio Cristo, aceitando brandamente as penalidades impostas pelo poder.

É fato notável nos textos de teóricos do direito divino a profusão de temas retirados de passagens bíblicas, que ajudaram a fazer do exercício do poder régio um complexo problema de interpretação. Muitas situações vividas cotidianamente pelos grandes vultos políticos contemporâneos eram interpretadas à luz das Sagradas Escrituras. Sir Robert Filmer, por exemplo, no livro Patriarcha, tomava como fundamento de sua teoria a instituição patriarcal, da forma como fora fixada no primeiro livro do Velho Testamento, o Gênesis. ${ }^{15}$ Acerca da doutrina do patriarcado na obra de Filmer, Paul Hazard escreveu: "Para defender o poder cambaleante dos Stuarts, não se deixara de apelar para as teorias. Tinham-se exumado, entre outros escritos em que se afirmavam a legitimidade do poder absoluto, os de um polemista vigoroso que, pelo meio do século, defendera valentemente a

\footnotetext{
${ }^{15}$ A crítica de John Locke ao Patriarcha é uma profunda "cirurgia" filosófica que dissipa todos os miasmas absolutistas da teoria filmeriana no "Primeiro Tratado sobre o Governo". Ver LOCKE. Dois Tratados sobre o Governo. São Paulo: Martins Fontes, 2002.
} 
causa real. Robert Filmer pregava a submissão, a obediência, dizendo que um governo misto não levaria senão à desordem, que os súditos não tinham qualquer direito à rebelião; que Hobbes não tinha razão nos seus princípios, mas tinha-a perfeitamente nas suas consequências. Põe-se de novo Filmer em moda; e até se edita em 1680, e se reedita no decurso dos anos seguintes, a grande obra deste sábio, Patriarcha, que tornava claro como o dia que a autoridade dos reis é o prolongamento da autoridade paterna: contra o próprio rei, nenhum filho, temente a Deus e aos homens, ousaria revoltar-se". ${ }^{\prime 6}$

Acerca das origens mais remotas do poder por direito divino, é preciso dizer que se trata de tese galicana. Portanto, as origens devem ser procuradas no final da Idade Média, época em que os escritores realistas, no esforço de refutar as pretensões do papado à concentração de poderes expressa em ideias como a Teoria dos dois gládios, desenvolveram uma nova noção de soberania. No conflito com Roma pode-se buscar as primeiras ideias que iriam dar consistência ao direito divino dos reis. Apesar das origens remotas no passado, foi apenas na segunda metade do século XVI que a difusão do direito divino iniciou-se como corpo doutrinal responsável pela elevação do poder régio "a uma altura decisivamente acima da fidelidade limitada e recíproca da suserania real medieval", segundo Perry Anderson. Para esse autor, "(...) o século XVI encerrou-se, nos principais países, sem que a forma acabada do absolutismo existisse em qualquer deles (...). Na verdade, o próprio termo 'absolutismo' era uma denominação imprópria. Nenhuma monarquia ocidental gozara jamais de poder absoluto sobre seus súditos, no sentido de um despotismo sem entraves. Todas elas eram limitadas, mesmo no máximo de suas prerrogativas, pelo complexo de concepções denominado direito 'divino' ou 'natural'. A teoria da soberania de Bodin, que dominou o pensamento político europeu por um século, corporifica eloquentemente essas contradições do absolutismo" ${ }^{17}$

Às ideias de soberania articuladas pelos escritores papistas da Idade Média, os partidários das monarquias modernas opunham a tese de não ser o papa, mas o rei, o legítimo soberano por desígnio expresso de Deus. Embasando essa justificativa, estava a ideia acerca da ascendência por nascimento: os reis, ao contrário dos papas, não eram escolhidos por um conselho de homens, mas pelos mistérios ocultos do nascimento, mistérios que conferiam à linhagem reinante um diferencial que a colocava em situação superior a qualquer outra instância terrena. A teologia política do direito divino implicava, fundamentalmente, a ideia de soberania, que já aparecia tanto nas pretensões de hegemonia universal da Igreja, e que se tornou na justificativa de liderança nacional das monarquias modernas.

${ }^{16}$ HAZARD, Paul. Crise da consciência europeia. Lisboa: Cosmos, 1974. p. 215s.

17 ANDERSON, Perry. Linhagens do Estado absolutista. São Paulo: Brasiliense, 1985. p. 48. 
Apesar de alguns papas, como Gregório VII, terem declarado, na Idade Média, que todo governo secular era de origem diabólica, a consciência popular estava regulada pelo sentimento de que o poder do rei tinha a sua origem em Deus, e que prestar-lhe obediência era um dever praticado pelos grandes vultos do cristianismo. Uma prescrição como essa, apesar de sua incontestável autoridade, não constituía por si só uma teoria, mas já carregava os fundamentos, a crença, que lhe propiciaria desenvolver-se, sob circunstâncias favoráveis. É preciso lembrar que nem todos os teóricos modernos da soberania do poder régio foram defensores do direito divino. Maquiavel, no que diz respeito especificamente ao Príncipe, e mais de cem anos depois dele, Thomas Hobbes, operaram um verdadeiro curto-circuito nas ideias políticas tradicionais, ao abolirem justificativas religiosas para o poder monárquico.

Inegavelmente, todas as grandes mudanças nas atitudes coletivas provocadas pela insegurança dos séculos XVI e XVII levavam à existência de um sentimento de maior lealdade ao rei e à monarquia. Assim foi que, no século XVI, mesmo que se encontrassem melhor organizados, os Estados nacionais europeus ainda enfrentavam insurgências políticas, guerras civis e conflitos internacionais, fatores que fixaram com mais intensidade os anseios coletivos por paz e segurança. No século XVII, o campo se tornara favorável ao absolutismo, atingindo a lealdade ao soberano o seu ponto máximo de desenvolvimento. "A lealdade pessoal ao soberano", escreveu Strayer, "atingiu o seu ponto culminante com a doutrina do direito divino. Se um único homem, claramente escolhido por Deus, tinha o direito de reinar num dado momento, então todas as pessoas de reto pensamento the deviam obediência incondicional. Em épocas anteriores, as pessoas podiam aceitar a ideia de que a monarquia era a melhor forma de governo, sem porém pensarem que o rei devesse em tudo ser obedecido, nem que qualquer monarca era insubstituível. A aceitação da teoria do direito divino veio tornar ilegítima qualquer resistência à vontade do soberano, contribuindo assim para fortalecer o Estado" ${ }^{18}$ A profunda e geral adesão à realeza sagrada não somente fortaleceu o Estado monárquico nascente, como tornou reprovável e ilegítima a menor resistência à vontade soberana do príncipe cristão. As doutrinas do direito divino dos reis acabaram por desenvolver um emaranhado de símbolos sobre o poder e as relações sociais. Nesse sentido, foram responsáveis por boa parte da estabilidade do absolutismo. Entretanto, não se pode deixar de reconhecer que não houve um tempo próprio ao sistema absolutista europeu. Na verdade, houve vários pontos de partida, e diferentes pontos de chegada, segundo a cronologia proposta por Perry Anderson. ${ }^{19}$

18 STRAYER, Joseph. As origens medievais do Estado Moderno. Lisboa: Gradiva, s. d. p. $112 \mathrm{~s}$.

19 Cf. ANDERSON, Perry. Linhagens do Estado absolutista. Op. cit. 
Na esteira de uma concepção teológica da história, a ordenação da sociedade idealizada pelo pensamento político moderno apareceu como cópia equivalente da ordem celeste: um modelo necessariamente hierarquizado, em que o humano e o divino deviam harmonizar-se. $\mathrm{O}$ direito divino dos reis representou muito mais que uma simples auréola sagrada para o poder monárquico. Criou representações da política e da sociedade pelas quais os privilégios, as hierarquias e as divisões entre os que mandavam e os que obedeciam foram aceitas como dados naturais, eternos e imutáveis.

Dito isso, é despropositado considerar o absolutismo de direito divino como algo retrógrado ou mesmo ridículo. Hoje, é mais criticável a perda do sentido essencial de que, a partir da segunda metade do século XVI, os que fundamentaram ou de alguma forma favoreceram o poder dos reis da Europa Moderna eram homens instruídos e conscientes em relação aos mais importantes problemas práticos de sua época. Julgado em relação às circunstâncias que o produziram, e com as doutrinas que lhe disputaram o terreno político, o direito divino dos reis poderá se afigurar como algo necessário e muito razoável. Fora desse ponto de vista, ou seja, do ponto de vista a-histórico, qualquer teoria política necessariamente parecerá ridícula na proporção direta ao tempo em que tiver perdido a sua validade prática, acentuava há cerca de um século o historiador inglês John Neville Figgis. Certamente, não é essa a melhor maneira de avaliar a importância cultural e o sentido histórico de uma crença política há muito abandonada. É anacrônica a suposição de que, devido ao fato de uma teoria ter caído em completo desuso, jamais tivesse elementos que a abonassem, salvo os interesses e as maquinações de uma elite politicamente ativa e bem formada.

Com efeito, uma doutrina com as características como as da que foi exposta, teve seus pressupostos fundados tanto na teologia quanto na política e, portanto, não pode ser julgada às pressas e segundo os valores de nossa própria época, um tempo em que tais categorias já se encontram totalmente separadas. Diante do tema, é preciso adquirir o sentido histórico de que as doutrinas do direito divino dos reis pertenceram a uma época em que o ato de fazer política - e teoria política - implicava trabalhar com registros de natureza transcendente. Ao tempo dos reis absolutistas, tais elementos encontravam-se confundidos, embaralhados, e o grau de incisão de uma situação como essa na vida diária era tal que, até mesmo para fins cotidianos e utilitários, forçoso era encontrar justificativas teológico-religiosas caso houvesse a pretensão de fazer-se aceito.

Um fato comum a boa parte do século XIX, no que diz respeito ao pensamento político como tema histórico, foram as atitudes voltadas para a ridicularização das cerimônias monárquicas e do direito divino dos reis. Inúmeros foram os historiadores e escritores políticos que não pouparam recursos retóricos satíricos ao abordarem o assunto. No século XIX, não houve nenhuma outra corrente de pensamento político contra a qual se 
escreveu com tanta zombaria - que devemos entender por seriedade militante - como a do direito divino dos reis. Nesse ponto, recordo-me da crítica endereçada por Collingwood àqueles historiadores que escrevem histórias sem sentido histórico. Ele observa que quando os historiadores atuais "apreendem" o sentido que os gregos antigos faziam do conceito de "barco" e o "traduzem" para a ideia contemporânea de "barco a vapor", tudo indica que incorreram em algum equívoco. Mas, quando se critica esse equívoco de interpretação, os historiadores respondem que isso apenas é sinal inequívoco de que os gregos antigos possuíam estranhas e equivocadas ideias acerca de barcos a vapor. A lição bastante singela de Collingwood: ideias, crenças e conceitos devem ser compreendidos em seu próprio lugar de elaboração bem como em meio às mudanças e/ou deformações pelas quais passam no tempo. ${ }^{20}$

Confrontada com os olhos e o ponto de vista político de hoje, dificilmente se encontraria uma doutrina tão despropositada quanto a do direito divino dos reis. Aliás, tal alteração de perspectiva é coisa que data do já distante século XVIII. Nas palavras de Jean Starobinski, "Se o sentimento do direito divino é ainda inabalável num Luís XIV, a conivência instável da convicção real e da submissão deslumbrada dos povos tende a romper-se no século XVIII. Os desastres guerreiros do Rei Sol, os escândalos da Regência, a instalação da Casa de Orange no trono da Inglaterra marcam o início de uma época em que os ritos majestosos da soberania vão ser suplantados por seus simulacros. Tanto o príncipe quanto os que o rodeiam sentem o cerimonial como uma convenção e um artifício e não mais como a criação mágica de uma ordem absoluta". ${ }^{21}$

Endereço do Autor:

Rua Marília, 233

Bairro Jd. Veraliz

86062-560 Londrina - PR

e-mail: marcos.lopes@pq.cnpq.br

${ }^{20}$ Cito de memória esta passagem. Acerca da obra teórica de Collingwood, em especial sua hermenêutica, ver: RIDLEY, Aaron. R.G. Collingwood. São Paulo: Editora Unesp, 2001.

${ }_{21}^{21}$ STAROBINSKI, Jean. "O fausto e o luxo". In: —_. A invenção da liberdade. São Paulo: Editora Unesp, 1994. p. 22. 